\title{
Ecological Aspects of Petroleum Industry
}

\author{
Sergey I. Vasiliev and Lyubov A. Lapushova* \\ Siberian Federal University \\ 79 Svobodny, Krasnoyarsk, 660041, Russia
}

Received 14.07.2016, received in revised form 21.10.2016, accepted 18.11.2016

The paper analyzes the consequences of oil and petrol products pollution, provides the classification by level of contamination, and proves insufficiency of the classification used for Eastern Siberia grounds. The article suggests the ways to improve the classification in additional gradation of low and medium contamination level taking into consideration the altitude position of the ground, condition and thickness of moist layer, humus, mineral layer, composition of parent materials.

Keywords: polymer sorbent, oil contaminated soil, petrol contamination level.

Citation: Vasiliev S.I., Lapushova L.A. Ecological Aspects of Petroleum Industry, J. Sib. Fed. Univ. Eng. technol., 2016, 9(8), 1366-1372. DOI: 10.17516/1999-494X-2016-9-8-1366-1372.

\section{Экологические аспекты деятельности нефтегазовой отрасли}

С.И. Васильев, Л.А. Лапушова Сибирский федеральный университет Россия, 660041, Красноярск, пр. Свободный, 79

Рассмотрень последствия загрязнения нефтью и нефтепродуктами, приведена классификаиия по степени загрязнения, обоснована недостаточность используемой классификаиия для грунтов Восточно-Сибирского региона. Предложена доработка классификащии по дополнительной градащии слабой и средней степеней загрязнения с учетом высотного положения грунта, состояния и толщины влажного слоя, гумусного, минерального слоя, состава материнских пород.

Ключевые слова: полимерный сорбент, нефтезагрязненный грунт, степень загрязнения почвы нефтепродуктами.

Охрана природной среды в нефтегазовой отрасли - понятие, ставшее своеобразным лозунгом и весьма выгодной темой многих публикаций и выступлений, характерной вехой для нашей цивилизации со второй половины XX в. и в настоящее время продолжает оставаться одной

(C) Siberian Federal University. All rights reserved

* Corresponding author E-mail address: S-vasilev1@yandex.ru, Lyubov_Lapushova@mail.ru 
из первоочередных задач современности. Существует мнение, что некоторые радикальные организации защитников окружающей среды занимаются экотерроризмом с целью повлиять на общественное мнение и многие экологические опасности ими преувеличены, при этом их цель не решение экологических проблем, а самореклама, конечным результатом которой является получение финансирования на свою деятельность. Деятельность таких организаций наносит непоправимый ущерб решению экологических проблем, вырабатывая негативное отношение общества к мониторингу экологической обстановки как к явлению обогащения компаний, активно эксплуатирующих эту тему.

Сибирь - основной нефтедобывающий регион страны, которым останется на ближайшие десятилетия. Именно здесь наиболее ярко проявляются все негативные последствия интенсивной добычи «черного золота» для окружающей природной среды. Мировой и отечественный опыт разработки месторождений углеводородного сырья свидетельствует о том, что разливы нефти - неизбежное следствие применения современных технологий [1]. В настоящее время от 1,0 до 16,5 \% нефти и продуктов ее переработки теряется при добыче, подготовке, переработке и транспортировке. В атмосферу поступает $\sim 65 \%$ загрязнений, в воду -20 , в почву -15 . Примерно половина нефтяной органики из воздуха оседает в районах добычи и воздействует на природную среду через почву и воду.

Проблема борьбы с разливами нефти и нефтепродуктов при авариях в настоящее время актуальна для всего мира. При разливе нефти наибольшую опасность представляет распространение ее на больших площадях, приводящее к нарушениям экологического баланса и делающее невозможным нормальное функционирование биологических систем и технических средств в течение длительного времени [2].

Загрязнение территорий нефтью, минерализованными водами и химическими реагентами по масштабам воздействия на биогеоценозы занимает ведущее место среди техногенных факторов, сопутствующих нефтедобыче: на его долю приходится 42,3 \% всех нарушенных земель. Аварийные выбросы нефти и минерализованных пластовых вод специалисты оценивают как главную экологическую опасность при обустройстве месторождений углеводородного сырья.

В число основных источников техногенного воздействия на природу, как известно, входят предприятия топливно-энергетического комплекса, тяжелая промышленность и транспорт. Каждая из этих отраслей вносит свой вклад в негативное воздействие на окружающую среду.

Среди основных причин попадания нефти в окружающую природную среду можно выделить порывы коллекторов системы нефтесбора, утечки из шламовых амбаров через нарушенную обваловку, разбрызгивание и разлив при поломке задвижек, разбрызгивание при фонтанировании с факелов, утечки с кустовых и производственных площадок различных технологических объектов.

Нефть и нефтепродукты отнесены к самым опасным загрязнителям природных вод. Известная роль в загрязнении рек и водоемов нефтью принадлежит географическим особенностям нефтяных месторождений [3]. Одна из них заключается в том, что месторождения рассредоточены на значительной территории Сибири. Многочисленные участки добычи, подготовки и транспорта нефти расположены на больших расстояниях.

Для оценки воздействия нефтяного загрязнения на наземные биогеоценозы и планирования рекультивационных мероприятий используется классификация нефтяных разливов. В ее 
основу положены концентрация загрязнителя (нефти), давность и площадь загрязнения, биотопическая приуроченность. На основе этого предложена схема деления интенсивности нефтяного загрязнения почв, базирующаяся на деградационно-восстановительных реакциях сообществ древесной и травянистой растительности, а также внешнего вида разлива.

Выделяют три степени загрязнения почв: слабая (концентрация нефти в лесной подстилке или верхнем 10-сантиметровом слое торфа до $20 \%$ ), средняя (20-40 \%) и сильная (более 40 \%). Загрязнение слабой степени чаще всего формируется при фонтанировании разорванных коллекторов либо это старые разливы средней степени. Разливы средней степени, как правило, представляют собой окраины разливов сильной степени. По давности загрязненные участки делятся на три группы: очень свежие (до 1 года с момента аварии), свежие (1-3 года) и старые (более 3 лет). К первой и второй группам относятся и старые, периодически обновляющиеся участки. По площади загрязнения выделяются мелкие разливы (до 0,1 га), средние $(0,1-1,0$ га) и крупные (более 1,0 га).

Для характеристики биотопического распределения загрязненных участков установлены следующие биотопы: болота (верховые и переходные, грядово-мочажинные болотные комплексы со сфагновобагульниковым сосняком на грядах); водные поверхности (озера и большие мелкорослой сосной) и безлесные сфагновые болота. На месторождениях Сибири преобладают мелкие по размеру разливы, но основная часть замазученной территории приходится на средние.

Это объясняется тем, что нефть, растекаясь по дренированной пересеченной поверхности, стекает узкими полосами от места аварии в понижения рельефа, пропитывая по ходу грунт. Участки леса подвергаются загрязнению как раз при миграции техногенных потоков с более высоких мест в более низкие. При разливах в зоне верховых грядово-мочажинных сфагновых болот нефть беспрепятственно разливается по большой площади, что обусловлено незначительной миграцией углеводородов в глубь сильно обводненных болотных почв.

Этот факт подтверждает и анализ биотопической приуроченности замазученных территорий, где больше половины нефтезагрязненной площади приходится на болотные биотопы (52,59 га, или 58,2 \%) и лишь 23,61 га (26,1 \%) на лесные почвы.

Анализируя распределение нефтяных разливов по давности загрязнения на производственной территории, можно сказать, что на момент обследования большая часть свежих разливов говорит о недостаточных мерах по ликвидации последствий аварий и рекультивации.

Территория большей часть нефтяных месторождений располагается не на торфяных почвах, поэтому классификация степени загрязнения почв по глубине проникновения в торф не во всех случаях применима, это в первую очередь касается суглинистых и глинистых грунтов. Для этих грунтов классификацию степени загрязнения целесообразно проводить по процентному содержанию нефти в грунте, что применимо и для торфа.

О степени загрязнения почвы нефтью и нефтепродуктами и о зависимости этого загрязнения от их содержания можно судить по данным таблицы.

На основании опубликованных отечественных и зарубежных данных скорости самоочищения нефтезагрязненных почв разных природных зон при уровне загрязнения 5000 мг/кг

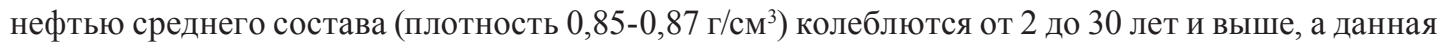
концентрация нефти характеризует только среднюю степень загрязнения. Следует отметить, 
Таблица. Степень загрязнения почвы нефтепродуктами

\begin{tabular}{|c|c|}
\hline Загрязненность почвы & Содержание нефти, мг/кг \\
\hline Незагрязненная & $<400$ \\
\hline Слабая & $3000-6000$ \\
\hline Средняя & $6000-12000$ \\
\hline Сильная & $12000-25000$ \\
\hline Очень сильная & $>25000$ \\
\hline
\end{tabular}

что градация степени загрязнения почвы нефтью не учитывает высотное положение грунта, состояние и толщину влажного слоя, гумусного, минерального слоя, состав материнских пород. Кроме этого, слабая и средняя степени загрязнения нуждаются в дополнительной градации с учетом перечисленных факторов.

При рассмотрении распределения площадей разливов необходимо подчеркнуть, что крупных (более 1 га) разливов всего 26 \%, но 85 \% замазученной территории приходится именно на них. При этом площадь среднего крупного разлива почти 4 га. Основное число разливов имеют размеры $0,1-1$ га.

Таким образом, по статистическим характеристикам нефтяного загрязнения в среднетаежной зоне Сибири можно сделать вывод о том, что наибольшее число разливов нефти имеет давность более 3 лет и относится к экологическому ущербу прошлых лет, при этом источник и виновника загрязнений практически невозможно установить, что приводит к необходимости устранения их за счет местного бюджета.

Сведения о типологии разливов имеют большое практическое значение при планировании рекультивационных работ и разработке наиболее экологически целесообразных мероприятий, выборе сорбционных материалов и технологии обработки, а также при выборе первоочередных объектов, представляющих наибольшую опасность как вторичные источники нефтяного загрязнения природной окружающей среды [1].

Важной составляющей частью практически всех национальных программ перспективного экономического и социального развития в условиях энергетическо-экологических кризисов во всем мире и в России является экономия и рациональное использование различных сорбентов, включая сорбирующие материалы и изделия из них [2].

При этом спектр сорбентов, используемых для локализации разливов, их сбора, достаточно широк, известно более 120 сорбентов, в числе которых как отечественные, так и зарубежные сорта, выпускаемые и используемые в практической деятельности хозяйствующих субъектов нефтегазовой отрасли.

Сорбционная способность сорбентов, полученных на основе полимерных композиций, проверена на ряде нефтепродуктов и их производных, а также на жидких химических и на сильнодействующих ядовитых веществах. Полимерные сорбенты «Униполимер-М», «Унисорб», предназначенные для локализации и очистки поверхностей гидросферы, грунта, сточной, оборотной и технологической воды, токсичных, ядовитых соединений при проведении плановых и профилактических мероприятий, имеют общую основу. При этом добавки био- 
штамма в сорбенте «Униполимер-Био» в 4 раза уменьшают время рекультивации нефтепораженных участков почвы, а «Униполимер-Ферро» упрощает технологию нанесения сорбента и сбора сорбата.

Кроме полимерных сорбентов в нефтегазовой отрасли в сорбентов применяются опилки, терморасширенный торф, солома, вспученный перлит и вермикулит, тонковолокнистые материалы из лавсана, акрилонитрила и полипропилена [1] с емкостью от 4 до 30 массовых частей на одну весовую часть поглотителя. Особенностью волокнистых материалов является многократное использование после извлечения поглощённых нефтепродуктов или других органических жидкостей в каландрах, центрифугах или других устройствах.

В настоящее время одной из сложных и нерешённых проблем в нефтяной промышленности в процессе ликвидаций аварий и их последствий на транспортных магистральных нефтепроводах является сбор и очистка загрязнённой воды и грунта нефтью. С повышением экологических требований очистка загрязнённых объектов от нефтепродуктов весьма актуальна и требует принятия неотложных решений по созданию специальных технологий и способов с применением профилактических мер по локализации, сбору и утилизации нефти.

Несмотря на разнообразие природных и искусственных сорбентов, в настоящее время ввиду нетехнологичности получения, нанесения, сбора, сложности утилизации и малой эффективности они не нашли широкого применения в нефтяной промышленности.

Основной задачей экологической безопасности в системе управления окружающей среды (СУОС) при эксплуатации магистрально-промысловых нефтепроводов, нефтеперекачивающих и наливных станций нефтегазового комплекса является разработка и внедрение импортозамещающих сорбирующих материалов различных модификаций. Кроме того, большую роль сыграло ужесточение требований к экологической безопасности нефтепромыслов Восточной Сибири, включая заповедные регионы Байкала и Дальнего Востока. С точки зрения решения проблем внедрения экологических природоохранных технологий производства сорбирующих материалов и изделий наиболее перспективным и эффективным сорбционным материалом признаны вспененные карбамидные полимерные сорбенты различных модификаций. Повышает конкурентоспособность карбамидных сорбентов с другими видами зарубежных сорбентов, такими как «Эластек» (США), «Зорболайт» (Франция), «Пит-сорб» (Канада) и т.д., высокая стоимость зарубежных сорбентов, сравнительно низкий показатель нефтеемкости, гидрофобности, плавучести, термостойкости с обязательным требованием утилизации, что приводит к большим трудовым затратам и недостаточной технологичности применения этих сорбентов в условиях Сибири. На базе проведенного суммарного анализа по критериям ценанефтеемкость-технологичность и экологичность авторами была предложена эквивалентная технология и составы композиций для получения широкой линейки полимерных сорбентов с улучшенными физико-механическими, эксплуатационными и экономическими показателями.

Проведённые в Институте нефти и газа СФУ многолетние исследования по изысканию таких сорбентов показали, что наиболее эффективным и технологичным сорбентом является полимерный сорбент, полученный на основе водорастворимой карбамидоформальдегидной смолы, эмульгирующих и стабилизирующих добавок. Высокие сорбционные свойства этого сорбента, его избирательная способность объясняются хорошей олеофильностью материала, 
большой удельной поверхностью, низкой плотностью, открытой ячеистой пористостью и стопроцентной плавучестью, позволяют рекомендовать его для широкого внедрения в производства по экологической защите окружающей среды от нефтяного загрязнения.

В настоящее время с учетом импортозамещения на рынке России представлены под торговой маркой сорбенты серий «Униполимер-М», «Меном», «Унисорб», к достоинствам которых можно отнести хорошие физико-механические и сорбционные свойства, низкую стоимость и высокую технологичность [4].

Задачей настоящих исследований выступает разработка композиций для получения модифицированных полимерных сорбентов различными способами с возможностью улучшения физико-механических и эксплуатационных свойств сорбентов с одновременным снижением их стоимости с учетом использования отходов производств.

Использование в качестве наполнителя магнетита в композиции «Униполимер-Ферро» позволило получить принципиально новые свойства полимерного сорбента, к которым следует отнести повышение технологичности нанесения и сбор сорбента с помощью магнитных и электромагнитных устройств.

Применение современных технологий и аппаратуры своевременного обнаружения, локализации аварийных разливов нефти, нефтепродуктов наряду с совершенной системой управления производством и комплексом мер по защите воздуха, воды и почв, применением эффективных сорбирующих материалов позволит свести к минимуму отрицательное воздействие на окружающую среду. При этом концентрация загрязняющих веществ на добывающих и перерабатывающих нефтяных предприятиях отрасли не будет превышать предельно допустимой концентрации, предусмотренной существующими нормативами, в промышленных зонах и населенных пунктах.

\section{Вывод}

Классификация по процентному содержанию нефти или нефтепродуктов требует доработки в части дополнительной градации слабой и средней степеней загрязнения с учетом высотного положения грунта, состояния и толщины влажного слоя, гумусного, минерального слоя, состава материнских пород.

\section{Список литературы}

[1] Melkozerov W. M., Vasilyev S. I.. Umweltschutz und rationelle Mining bei der Entwicklung, die Ausbeutung von öl-Lagerstätten, Transport von Erdöl und Erdölprodukten. Deutschland: Lambert Academic Pablishing, 2011. 286 S.

[2] Васильев С.И. Побочное влияние карбамидных поропластов на аквабионты при утеплении грунтов Сибири. Защита окружающей среды в нефтегазовом комплексе, 2012, 9, 4247. [Vasilyev S. I. Nebensächlicher Effekt schaumstoffe auf mikroorganismen bei der Dämmung der Böden Sibiriens. Umweltschutz im erdl-und erdgaskomplex, 2012, 9, 42-47. (in Russian)]

[3] Васильев С.И., Мелкозеров В.М., Вельп А.Я., Горбунова Л.Н., Саначева Г.С., Федотова А.С. Технология сорбционной и биологической очистки биосферы от загрязнений нефтепродуктами. Системы. Методы. Технологии. 2011, 11, 168-179. [Vasilyev S. I., Melkozerov W. M., Вельп A. J., Gorbunov L. N., Sanasheva G. S.., Fedotova A. S. Technologie Sorption und biologischen 
Reinigung gegen Verschmutzung der Biosphäre ölprodukten. System. Methoden. Technologie. 2011, 11, 168-179. (in Russian)]

[4] Васильев. С.И, Мелкозеров В.М. Некоторые особенности исследований эксплуатационных характеристик полимерных сорбентов, используемых в природоохранных технологиях. Защита окружающей среды в нефтегазовом комплексе. 2013,11, 24-28. [Vasilyev S. I., Melkozerov W. M. Studien Einige Eigenschaften Gebrauchseigenschaften von Polymeren Sorbentien, die in umweltfreundlichen Technologien. Umweltschutz im erdl-und erdgaskomplex. 2013,11, 24-28. (in Russian)]

[4] Мелкозеров В. М., Васильев С. И.,. Вельп А. Я. Исследование эксплуатационных характеристик модифицированных многоцелевых карбамидных поропластов. Защита окружающей среды в нефтегазовом комплексе. 2010. 8,34-39. [Melkozerov V. M., Vasilyev S. I.,. Вельп A. J. Servicedaten modifizierten Mehrzweck Effekt schaumstoffe auf . Umweltschutz im erdl-und erdgaskomplex. 2010. 8,34-39. (in Russian)]

[5] Лапушова Л.А. Васильев С.И. Результаты исследования структуры полимерных сорбентов «Униполимер-М» для ликвидации техногенных разливов нефти и нефтепродуктов. $3 a$ щиита окружающей среды в нефтегазовом комплексе, 2015, 6, 17-21. [Lapuchova L. A. Vasilyev S. I. Ergebnisse der Untersuchung der Struktur von Polymeren Sorbentien «Униполимер-М» für die Beseitigung der vom Menschen verursachten ölverschmutzungen. Umweltschutz im erdl-und erdgaskomplex, 2015, 6, 17-21. (in Russian)]

[6] Мелкозеров В.М., Васильев С.И., Вельп А.Я., Горбунова Л.Н., Гуревич Ю.Л., Ладыгина В.П., Трусей И.В. Очистка нефтезагрязненных земель и водоемов Сибири с применением адсорбентов. Нефтепромысловое дело. 2010, 11, 58-62. [Melkozerov V. M., Vasilyev S. I., Вельп А. J., Gorbunowa L. N., Gurewitsch J. L., LADYGINA V. P., Trusej I. V. Reinigung нефтезагрязненных Flächen und Gewässern von Sibirien mit der Anwendung von Adsorbentien Ölfeld der Fall. 2010, 11, 58-62. (in Russian)]

[7] Мелкозеров В.М., Васильев С.И., Вельп А.Я., Крылышкин Р.Н., Марьянчик Д.И. Эксплуатационные свойства полимерных сорбентов. Журнал СФУ. Техника и технологии. 2011, 4(4), 369-379. [Melkozerov V. M., Vasilyev S. I., Velp A. J., Kriluskin R. N., Marjantic D. I. Anwendungstechnische Eigenschaften polymerer Sorbentien Magazin SFU. Technik und Technologie. 2011, 4(4), 369-379. (in Russian)]

[8] . Мелкозеров В.М, Васильев С.И., Лапушова Л.А.Патент РФ № 2587440 МПК В01J20/26 Композиция для получения сорбента на основе карбамидоформальдегидной смолы. [Melkozerov V. M,. Vasilyev S. I, Lapuchova L. A. Patent der Russischen Föderation № 2587440 IPC B01J20/26 Zusammensetzung zur Herstellung von Sorptionsmittel auf Basis Harz. (in Russian)] 